\title{
Non-Radiographic Axial Spondyloarthritis (nr-axSpA): Advances in Classification, Imaging and Therapy
}

Philip C. Robinson · Raj Sengupta $\cdot$ Stefan Siebert

Received: December 4, 2018 / Published online: February 20, 2019

(C) The Author(s) 2019

\section{ABSTRACT}

Non-radiographic axial spondyloarthritis (nraxSpA) is a recently described form of axial inflammatory arthritis that has not caused substantial erosive damage to the sacroiliac joints. Nr-axSpA is associated with significant impairment in quality of life and, in a proportion of patients, it can evolve into ankylosing spondylitis (AS, also termed radiographic axSpA). The identification in the clinic of nr-axSpA has been made possible by advances in magnetic resonance imaging (MRI). Classification criteria for nr-axSpA have been proposed but there remains discussion in the international community regarding this. Studies are ongoing to further define the classification and diagnosis of nr-axSpA. There is much further research required regarding the optimal use of MRI in nr-axSpA, including distinguishing sacroiliac MRI changes in the

Enhanced Digital Features To view enhanced digital features for this article go to https://doi.org/10.6084/ m9.figshare.7649195.

P. C. Robinson ( $\square)$

Royal Brisbane and Women's Hospital, School of Clinical Medicine, University of Queensland,

Herston, QLD 4029, Australia

e-mail: philip.robinson@uq.edu.au

R. Sengupta

Royal National Hospital for Rheumatic Diseases, Bath, UK

S. Siebert

Institute of Infection, Immunity and Inflammation, University of Glasgow, Glasgow, UK normal population and the definition of a positive MRI in spinal disease. Non-steroidal anti-inflammatory drugs and physiotherapy are the core first-line therapy for nr-axSpA. Tumour necrosis factor inhibitors also play a very important role in treatment of patients with active nr-axSpA who do not respond to first-line therapy. Agents directed at interleukin-17, interleukin-23 and Janus kinase inhibitors are proving effective in AS with ongoing and planned studies in nr-axSpA. A great deal of active research is being undertaken in classification, imaging and therapy in nr-axSpA and so the future for improving the lives of patients with nr-axSpA is promising.

Keywords: Ankylosing spondylitis; Axial spondyloarthritis; Magnetic resonance imaging; Non-radiographic axial spondyloarthritis; Tumour necrosis factor inhibitor

\section{INTRODUCTION}

Non-radiographic axial spondyloarthritis (nraxSpA) is an important, albeit recently described, member of the spondyloarthritis (SpA) family of conditions. While ankylosing spondylitis (AS) has long been a recognised clinical entity due to the clear radiographic changes present in the sacroiliac joints (SIJs), it was recognised that there is often a period where classic signs and symptoms of axial inflammatory disease are present in the absence of radiographic changes in the SIJs fulfilling the 
modified New York criteria [1]. Khan and colleagues first described this condition in 1985, calling it "spondylitic disease without radiologic evidence of sacroiliitis" [2]. It was subsequently given the name non-radiographic axial SpA to recognise that not all cases proceeded to radiographic axSpA/AS $[3,4]$. This article is based on previously conducted studies and does not contain any studies with human participants or animals performed by any of the authors.

\section{NOMENCLATURE}

The nomenclature has evolved with the recognition of nr-axSpA. AxSpA is an umbrella term which includes radiographic axSpA (also referred to as AS) and nr-axSpA. Patients can also have combined features of axial SpA and peripheral SpA.

\section{CLASSIFICATION}

The publication by the European-based Assessment of SpondyloArthritis International Society (ASAS) of their 2009 axSpA classification criteria was a significant, and somewhat controversial, milestone in the genesis of nr-axSpA [3, 4]. The ASAS group proposed that a patient could be classified as having axSpA by fulfilling one of two arms after satisfying the entry criteria of being less than 45 years old and having greater than 3 months of chronic back pain. The clinical 'HLA-B27 arm' allowed classification on the basis of a positive HLA-B27 test and two or more SpA features. These features are inflammatory back pain, arthritis, heel enthesitis, uveitis, dactylitis, psoriasis, Crohn's disease, good response to non-steroidal anti-inflammatory drugs (NSAIDs), family history of SpA or an elevated C-reactive protein (CRP). The imaging arm allowed classification on the basis of either a positive magnetic resonance imaging (MRI) or radiographic sacroiliitis and one or more SpA features from the aforementioned list. Patients can be classified as nr-axSpA if they meet this classification criteria set but their radiographic SIJ changes are not bilateral grade 2 or unilateral grade 3 or higher. Patients can therefore be classified as nr-axSpA on the basis of either a positive MRI of the SIJ or by fulfilling the HLAB27 arm without any objective evidence of axial inflammatory disease. The latter in particular has led to some criticism of the criteria [5]. This has precipitated suggestions for modifications or improvements [6-11]. There is now a combined effort by the North American SpA group SPARTAN and the European ASAS group to run two large studies to further explore classification of SpA, termed the CLassification of Axial SpondyloarthritiS Inception Cohort (CLASSIC) studies.

It should, however, be noted that the above are all classification criteria for use in clinical research and are not diagnostic criteria. As such, these criteria should not simply be applied in a clinical setting as making a diagnosis of nraxSpA requires exclusion of other potential causes for the presenting symptoms or findings (both clinical and imaging).

\section{IMAGING IN NR-AXSPA}

The importance of imaging in the diagnosis of axSpA is well established. However, there has been a transition from the requirement for established radiographic abnormalities for diagnosis to identification of "inflammatory" abnormalities on MRI.

\section{Radiographs in axSpA}

Radiographic sacroiliitis is a late feature of axSpA, often occurring after many years of typical axial symptoms. Radiographs can only demonstrate bony changes which appear as a consequence of previous inflammation and typically include erosions and sclerosis adjacent to the joint line. Fulfilling the modified New York criteria (mNYC) for AS requires radiographic evidence of either bilateral grade 2 or unilateral grade 3 or 4 SIJ changes [1]. However, the complex anatomy of the sacroiliac joint makes interpretation of these radiographs difficult, with highly variable inter- and intra-rater reliability, even amongst expert readers [12].

Typical lesions seen at the vertebral level on the spinal radiographs of axSpA patients are 
erosions, sclerosis, squaring, syndesmophytes and ankylosis. These changes are thought to commence with entheseal inflammation involving the outer fibres of the annulus fibrosis leading to new bone formation, causing squaring of the vertebra and subsequently formation of syndesmophytes. In a small number of patients, the continued development of syndesmophytes and subsequent bridging at numerous levels may lead to the classic 'bamboo spine' appearance.

Use of scoring systems such as the modified Stoke Ankylosing Spondylitis Severity Score (mSASSS) has shown progression at a group level in the spine to occur at a slow and linear rate [13]. At an individual patient level, however, radiographic progression is highly variable with a study over 12 years showing that up to $25 \%$ of axSpA patients show no progression [14].

\section{MRI in axSpA}

The use of MRI for diagnosis of axSpA has been demonstrated in several studies [15-17]. MRI scans conducted for diagnosis of axSpA need to include fat-suppressed image sequences, such as short tau inversion recovery (STIR) or Dixon sequences, as these are essential to detect the typical active inflammatory lesions (bone marrow oedema (BMO) or osteitis) seen in axSpA. Whilst BMO lesions form the basis of ASAS criteria for a positive scan (defined as one area of $\mathrm{BMO}$ on at least two consecutive slices or at least two areas of BMO on a single slice), lesions such as capsulitis, enthesitis and synovitis are also seen [18]. More recent research reinforces the notion that inflammatory changes on an MRI should not be used in isolation to diagnose axSpA. In one study, up to $23 \%$ of healthy individuals and $57 \%$ of post-partum women met ASAS positive MRI criteria [19]. Other recent studies have shown high rates of BMO lesions in recreational runners, professional sports people and army recruits undergoing physical training $[20,21]$.

In more established disease, inflammatory lesions are thought to evolve into fatty lesions, which can be identified on the T1 sequence.
Whilst these lesions are less specific for axSpA because of their presence in degenerative disc disease, research has shown fatty lesions to be predictive of radiographic progression in axSpA [22]. The inclusion of spinal lesions seen on an MRI for diagnosis or classification of axSpA has yet to be agreed on, but the more corner lesions seen the more suggestive of axSpA, particularly in young patients or those with other features suggestive of axSpA [23].

A typical protocol for MRI scanning would include oblique scans through the sacroiliac joint with $\mathrm{T} 1$ and fat-suppressed sequences like STIR, SPUR or Dixon [24]. No contrast is required for diagnosis as it does not increase the diagnostic yield $[25,26]$. The inflammatory lesions needed for diagnosis are able to be seen on the fat-suppressed sequences. While scanning the lumbar, thoracic or cervical spine has not been shown to increase diagnostic yield for axSpA substantially it is often important to investigate the cause of a patient's back pain [27]. The advantage of using such a protocol is the short duration required for the patient to be in the scanner, but it is important to note that the lack of axial sequences may prevent detailed assessment of the presence of associated nerve root lesions.

The identification of BMO on MRI scans has been shown to be of prognostic value with a study showing a strong correlation between the severity/intensity of osteitis on the baseline MRI and the subsequent development of radiographic sacroiliitis 8 years later [28]. The extent of osteitis on an MRI has also shown an association with better responses to tumour necrosis factor inhibitor (TNFi) therapy [29].

Other MRI sequences, such as diffusionweighted imaging, for investigating axSpA have also been proposed but further research is required to demonstrate their value [30].

When patients present with typical symptoms like inflammatory back pain and their MRI scans are negative then these can be repeated in the future. Two recent studies demonstrated that being HLA-B27 positive and also male increase the chance that a repeat MRI scan at 3 or 12 months will be positive, but the conversion rate was low $7-14 \%[31,32]$. A study which performed SIJ needle biopsies also suggested 
that MRI scans have low sensitivity compared to histological changes, but SIJ needle biopsies are not performed in clinical practice so this study's conclusions lack generalisability [33].

\section{Other Imaging in axSpA}

Computerised tomography (CT) is an ideal modality for demonstrating structural changes in axSpA patients. However, the common use of this scanning technique is limited by its significant ionising radiation dose for the patient. Newer low dose CT modalities are being investigated with promising results [34].

MRI scans are the mainstay of diagnostic imaging in nr-axSpA allowing earlier diagnosis than plain radiographs. However, imaging must not be used in isolation to make the diagnosis of axSpA. In the correct clinical context, MRI may also be used to assess levels of disease activity and thereby guide treatment decisions.

\section{THERAPY IN NR-AXSPA}

The pharmacological treatment paradigm of axSpA has progressed considerably with the advent of biologic disease-modifying antirheumatic drugs (bDMARDs). These drugs have exhibited excellent efficacy in patients who do not respond, or only partially respond, to NSAIDs. However, NSAIDs and physical therapy remain the cornerstones of initial treatment for all patients with axSpA, including those with nr-axSpA.

Patient symptoms and the presence of extraarticular manifestations of axSpA, like anterior uveitis, often drive the initiation and choice of treatment. For example, patients are more likely to take NSAIDs and perform stretches during an acute flare of their condition. In addition, assessing a patient to identify the presence of other causes of back pain is essential to ensuring the correct selection of pharmacotherapy-a patient may have coexisting degenerative disc disease or fibromyalgia, which might be optimally treated with analgesia or neuromodulatory drugs rather than escalation to bDMARDs [35-37].
Pharmacotherapy in nr-axSpA can be divided into analgesia and NSAIDs, conventional synthetic DMARDs (csDMARDs) and bDMARDs.

\section{Non-Steroidal Anti-Inflammatory Drugs}

NSAIDs have been used for many years for patients with axSpA and have been shown to improve disease activity and function $[38,39]$. Both traditional and cyclooxygenase (COX) 2 inhibitors are effective but these agents are known to be associated with adverse cardiovascular, renal and gastrointestinal events $[40,41]$. Patients with inflammatory bowel disease may need to avoid NSAIDs if they precipitate flares of gastrointestinal symptoms but they can be used safely in many patients, in discussion with their gastroenterologist [42].

NSAIDs have similar efficacy in nr-axSpA as they do in AS with an ASAS40 response of 35\% at week 4 . This demonstrates that although a substantial minority have a good response to NSAIDs there remains a large group who likely need additional therapy [43].

There remains controversy regarding the ability of NSAIDs to prevent radiographic progression. A study by Wanders and colleagues suggested that regular celecoxib prevented progression of the disease assessed by radiographs, compared to those taking celecoxib on an 'as required' basis [44]. However, a more recent randomised controlled study of diclofenac by Sieper and colleagues did not demonstrate any reduction of radiographic progression [45].

Many jurisdictions require the use of one or two different NSAIDs prior to being authorised to prescribe bDMARDs for patients with active axSpA. NSAIDs are effective for the majority of axSpA patients and should therefore be used as first-line pharmacotherapy, unless contraindications exist. It is also worth noting that most axSpA patients stop NSAIDs once they commence bDMARDs. However, studies have shown an added benefit of combining NSAIDs and bDMARDs, so NSAIDs should be considered in those with a suboptimal response to bDMARDs alone [38]. 


\section{Corticosteroids}

Corticosteroids are rarely effective for axSpA. One study showed that relatively high doses of prednisolone $(50 \mathrm{mg}$ ) daily was required for an effective response [46]. Targeted local steroid injections can often be effective for peripheral joint and entheseal involvement and have been shown to be effective for SIJ pain [47]. Topical and oral steroids are often used to treat flares of extra-articular manifestations, such as flares of uveitis or inflammatory bowel disease.

\section{Conventional Synthetic Disease- Modifying Drugs}

Conventional synthetic disease-modifying drugs (csDMARDs) such as methotrexate or sulfasalazine have not been shown to be effective for axial disease $[48,49]$. In some countries, where funding limits the use or availability of bDMARDs, csDMARDs are often used as firstline therapy. csDMARDs do, however, have a role in axSpA patents with peripheral disease, where they have been shown to be effective [50]. At present, there is little evidence to suggest that combined csDMARD and bDMARD therapy is more effective than bDMARD monotherapy in axSpA.

\section{TNF Inhibitors}

TNFi have transformed the treatment paradigm in $\mathrm{nr}-\mathrm{axSpA}$ as prior to their initiation many patients relied on NSAIDs only, which were not effective in all patients and led to complications as a result of chronic use. Following the successful trials of TNFi in rheumatoid arthritis (RA), their effectiveness in axSpA was investigated, with favourable results, in AS and subsequently in nr-axSpA [51]. These drugs are, however, expensive with potential side effects, and therefore several guidelines have been formulated to guide prescription by rheumatologists [52-54]. Table 1 shows the results of clinical trials of TNFi in nr-axSpA [55-58].

Adalimumab, etanercept, certolizumab, golimumab and infliximab are licenced for, and widely used, in AS. Adalimumab, certolizumab, etanercept and golimumab have indications for nr-axSpA in Europe, while etanercept and golimumab have indications for nr-axSpA in Australia.

Studies have shown that approximately 50\% of axSpA patients treated with a TNFi achieve an Assessment in SpondyloArthritis International Society 40\% improvement (ASAS40) [59]. Numerous studies have shown that baseline MRI positivity and/or elevated CRP is very important in predicting the response of patients with axSpA to TNFi $[55,56,60]$. Some studies even showed no significant difference from placebo in those with normal CRP and negative MRI. Predictors for a good response to TNFi include male gender, low Bath Ankylosing Spondylitis Functional Index (BASFI), raised CRP, shorter disease duration, HLA-B27 positivity and MRI changes [29, 61-63]. Ten-year drug survival for bDMARDs in axSpA has been reported to be $49 \%$ of treated patients [64]. Predictors of longer drug survival in this study were male gender, high CRP, and normalisation of CRP and resolution of MRI inflammation with TNFi.

Switching bDMARDs for those who have inadequate response to their first biologic has also become established in routine clinical care. The efficacy rates of subsequent bDMARDs are generally reduced, as shown in the Danish DANBIO registry, where the mean reduction in the Bath Ankylosing Spondylitis Disease Activity Index (BASDAI) at 6 months was 3 units for the index bDMARD, compared to 1.5 BASDAI units for the 3rd bDMARD [65]. Drug survival for sequential bDMARDs also follows a similar pattern with one study reporting the mean drug survival for the index bDMARD being 10.2 years compared to 5.5 years for the second [66]. The best switching strategy for biologics in axSpA remains unclear, with no randomised trials to inform this decision.

Unlike the situation in RA, stopping bDMARDs is not advisable in stable good responders with axSpA as most patients stopping TNFi will have a flare of their axSpA within 1 year [67]. However, dose optimisation of TNFi is becoming common place in routine clinical care and appears to be a viable approach, with a 
Table 1 Biological DMARD trials in nr-axSpA

\begin{tabular}{|c|c|c|c|c|c|c|}
\hline Drug & $\begin{array}{l}\text { Drug } \\
\text { mechanism }\end{array}$ & Inclusion criteria & $\begin{array}{l}\text { Patient no. } \\
\text { (active/placebo) }\end{array}$ & $\begin{array}{l}\text { Primary } \\
\text { endpoint }\end{array}$ & $\begin{array}{l}\text { ASAS40 } \\
\text { outcome } \\
\text { active/placebo } \\
(\%)\end{array}$ & $\begin{array}{l}\text { LDA/ } \\
\text { remission } \\
\text { rate }\end{array}$ \\
\hline $\begin{array}{l}\text { Adalimumab } \\
\text { (56) }\end{array}$ & $\begin{array}{l}\text { TNF } \\
\text { inhibitor }\end{array}$ & $\begin{array}{l}2009 \text { ASAS axSpA } \\
\text { criteria but not meet } \\
\text { AS criteria } \\
\text { No restriction on } \\
\text { disease duration } \\
\text { BASDAI } \geq 4 \\
\text { Total back pain } \geq 4\end{array}$ & $91 / 94$ & $\begin{array}{l}\text { ASAS40 } \\
\text { response at } \\
\text { week } 12\end{array}$ & $36 \% / 15 \%$ & \\
\hline $\begin{array}{l}\text { Golimumab } \\
\text { (55) }\end{array}$ & $\begin{array}{l}\text { TNF } \\
\text { inhibitor }\end{array}$ & $\begin{array}{l}2009 \text { ASAS axSpA } \\
\text { criteria but not meet } \\
\text { AS criteria } \\
\text { Disease } \\
\text { duration } \leq 5 \text { years } \\
\text { BASDAI } \geq 4 \\
\text { Total back pain } \geq 4\end{array}$ & $98 / 100$ & $\begin{array}{l}\text { ASAS20 } \\
\text { response at } \\
\text { week } 16\end{array}$ & $57 \% / 23 \%$ & \\
\hline $\begin{array}{l}\text { Certolizumab } \\
\text { (58) }\end{array}$ & $\begin{array}{l}\text { TNF } \\
\text { inhibitor }\end{array}$ & $\begin{array}{l}2009 \text { ASAS axSpA } \\
\text { criteria }^{\text {a }} \\
\text { BASDAI } \geq 4 \\
\text { Total back pain } \geq 4 \\
\text { No restriction on } \\
\text { disease duration } \\
\text { Elevated CRP or } \\
\text { ASAS/OMERACT } \\
\text { MRI changes }\end{array}$ & $147^{\mathrm{a}} / 107$ & $\begin{array}{l}\text { ASAS } 20 \\
\text { response at } \\
\text { week } 12\end{array}$ & $47-48 \% / 16 \%$ & \\
\hline $\begin{array}{l}\text { Etanercept } \\
\quad(57)\end{array}$ & $\begin{array}{l}\text { TNF } \\
\text { inhibitor }\end{array}$ & $\begin{array}{l}2009 \text { ASAS axSpA } \\
\text { criteria but not meet } \\
\text { AS criteria. } \\
\text { Disease } \\
\text { duration }>3 \text { months } \\
\text { and }<5 \text { years } \\
\text { BASDAI } \geq 4\end{array}$ & $106 / 109$ & $\begin{array}{l}\text { ASAS40 } \\
\text { response at } \\
\text { week } 12\end{array}$ & $32 \% / 16 \%$ & \\
\hline
\end{tabular}

CRP C-reactive protein, $M R I$ magnetic resonance imaging; 'ASAS/OMERACT MRI' MRI changes meeting the ASAS/ OMERACT definition of sacroiliitis, BASDAI Bath Ankylosing Spondylitis Disease Activity Index, LDA low disease activity

a This trial included both AS and nr-axSpA, but only the nr-axSpA results are reported in the table 
recent study showing that $58 \%$ of axSpA patients were able to reduce dose at 1 year [68].

The ideal combination and timing of initiation with NSAIDs and bDMARDs to prevent radiographic progression of axSpA need further evaluation. There is some evidence that TNFi inhibit radiographic progression in AS; however, the slow progression of spinal radiographic change in axSpA makes demonstrating this change logistically challenging [69-71]. Reassuringly, after nearly 2 decades of bDMARD use in rheumatology, there are no significant or new safety signals that have become apparent.

While the TNFi have transformed the management of axSpA, there remains significant unmet need for this chronic, lifelong condition. A significant number of patients fail to respond to or tolerate their first TNFi, while of those who do respond, many only have a partial response or lose efficacy over time. Therefore, there remains a need for treatments in axSpA beyond those targeting TNF.

\section{FUTURE THERAPY IN NR-AXSPA: IL- 17, IL-23 AND KINASE INHIBITORS}

The TNFi were initially developed for RA and subsequently adopted and shown to be efficacious for a range of immune-mediated inflammatory diseases, including AS and nr-axSpA. However, the clinical picture in axSpA is distinct from that in RA, with the musculoskeletal picture characterised by enthesitis and axial involvement, rather than synovitis, and the presence of characteristic extra-articular manifestations, such as psoriasis, uveitis and inflammatory bowel disease (IBD), shared with the other SpA conditions but not with RA. Genome-wide association studies, tissue analysis and preclinical models have identified the key role of the IL-23/-17 pathway in the pathogenesis of SpA, including axSpA. Therapies targeting this pathway in psoriasis have led to remarkable improvements, in excess of those seen with TNF inhibitors. These therapies were therefore also tested across the SpA spectrum, starting initially in psoriatic arthritis (PsA), where they demonstrated similar levels of efficacy to those seen with TNFi and are now established in clinical practice for these conditions, although they have not achieved the same levels of high hurdle response seen in the skin.

As a result of the distinct regulatory licensing requirements for AS and nr-axSpA, newer agents were first tested by the relevant pharmaceutical manufacturers in patients with active AS. The fact that nr-axSpA and AS are part of the axSpA spectrum, rather than distinct conditions, and the evidence from TNFi suggest that the results and lessons learnt from AS can be applied to nraxSpA. We therefore present the key studies of agents targeting the IL-23/-17 pathway in AS and comment on the likely implications of these results for nr-axSpA.

The efficacy and safety of secukinumab, an anti-IL-17A monoclonal antibody, for the treatment of active AS was demonstrated for secukinumab $150 \mathrm{mg}$ in two phase 3 randomised controlled trials [72]. The MEASURE 1 and 2 studies differed in the secukinumab loading regimen, being intravenous and subcutaneous, respectively. In both studies, the primary endpoint of ASAS 20\% improvement (ASAS20) at week 16 was achieved by $61 \%$ of the secukinumab $150 \mathrm{mg}$ group compared to $28-29 \%$ of the placebo group. Post hoc analysis of the MEASURE 2 study indicated that ASAS20 response rates at week 16 for secukinumab $150 \mathrm{mg}$ were $68 \%$ in TNFi-naïve patients and $50 \%$ for those with previous TNFi exposure [73]. Secukinumab also resulted in improved patientreported disease outcomes and health-related quality of life, which were sustained over 3 years with high retention rates [74-76]. Significantly, secukinumab treatment led to low radiographic progression on radiographs and regression of spinal inflammation on MRI [75, 77]. As a result of these studies, secukinumab has been widely licensed for the treatment of active AS.

Ixekizumab, another IL-17A antagonist, has subsequently also demonstrated efficacy in active AS in both a placebo-controlled phase 3 study in biologic-naïve patients and a placebo-/ active-controlled phase 3 study in patients with prior inadequate response or intolerance to TNFi $[78,79]$. Reassuringly, there were no new safety signals in the phase 3 studies of secukinumab or ixekizumab in AS beyond those seen 
with previous indications. There are currently ongoing phase 3 studies of secukinumab (ClinicalTrials.gov NCT02696031) and ixekizumab (ClinicalTrials.gov NCT02757352) in nr-axSpA.

Anti-IL-23 therapies have also been tested in AS following the suggestive pathogenetic role of IL-23 and the success of IL-23 inhibition in psoriasis and PsA. However, in contrast to IL17A inhibition, anti-IL-23 therapy with both p40 IL-23 (ustekinumab) and p19 IL-23 (risankizumab) inhibitors failed to demonstrate efficacy in phase 3 studies in axSpA and a phase 2 study in AS, respectively [80-82]. These initially surprising results are not fully understood and warrant further investigation; they may reflect tissue-discrete pathways, IL-23-independent IL17 responses in the spine or other, as yet poorly understood, mechanisms [82]. Taken together, these data suggest that, in contrast to IL-17A blockade, IL-23 inhibition is not an effective strategy for the treatment of AS and is unlikely to be taken further for nr-axSpA, although a phase $2 / 3$ study of tildrakizumab, another p19 IL-23 inhibitor, is still listed as active (ClinicalTrials.gov NCT03552276).

Small molecule inhibitors, and Janus kinase (JAK) inhibitors in particular, are entering the market for a number of immune-mediated inflammatory diseases, including RA, IBD and PsA. A 12-week phase 2 study of tofacitinib, an oral JAK $1 / 3$ inhibitor, in patients with active AS suggested efficacy, including improvement of MRI endpoints, with similar safety profile reported for other conditions [83]. A phase 3 study of tofacitinib in AS is ongoing (ClinicalTrials.gov NCT03502616). A phase 2 study of filgotinib, a highly selective JAK 1 inhibitor, also recently reported achieving the primary endpoint in patients with active AS, with significant improvements also observed for most secondary and patient-reported outcomes [84]. A phase $2 / 3$ study of upadacitinib, another selective JAK 1 inhibitor, is also underway in AS (ClinicalTrials.gov NCT03178487). These promising phase 2 studies require evaluation in a robust phase 3 programme, ideally also including active comparators. The optimal dose and selectivity of JAK inhibition in SpA remain to be determined [85]. There are currently no studies of JAK inhibitors for the treatment of nr-
axSpA registered but are likely to follow if phase 3 studies in AS are successful.

The identification of the important role of the microbiome in AS is also an area of active research [86] and there may well be future therapeutics developed to target the resident microbiome in nr-axSpA patients. Many researchers in the axSpA field believe that intestinal dysbiosis is the genesis of axSpA, so therapies targeting this area may even have the potential to prevent development of the full axSpA phenotype in the future [87]. With the strong genetic association of aminopeptidase genes ERAP1 and ERAP2 with AS, there are also active efforts underway to develop small molecule inhibitors of endoplasmic reticulum aminopeptidases to trial in axSpA [88].

In summary, advances in imaging have allowed the identification of disease much earlier in the course of patient symptoms. This has allowed classification and diagnosis of nraxSpA, but there is much further work required in these areas, especially in imaging definitions. NSAIDs and physiotherapy remain core firstline therapy, while biologics have transformed the treatment paradigm of patients with severe and active disease axSpA. The biologic and targeted therapies licensed for nr-axSpA are currently limited to TNF inhibitors. However, the success of IL-17A inhibitors and promising early phase results of JAK inhibitors in AS suggest that these are likely to join the armamentarium for $n r-a x S p A$ in the future. The future is very exciting for both diagnostic imaging and therapeutics in nr-axSpA.

\section{ACKNOWLEDGEMENTS}

Funding. No funding or sponsorship was received for this study or publication of this article.

Authorship. All named authors meet the International Committee of Medical Journal Editors (ICMJE) criteria for authorship for this article, take responsibility for the integrity of the work as a whole, and have given their approval for this version to be published. 
Disclosures. Philip C. Robinson has received research funding, given talks for and consulted to Abbvie, Eli Lilly, Janssen, Novartis, Pfizer, Roche, Sanofi-Genzyme and/or UCB. Raj Sengupta has received speaker fees, consultancy and/or grants from Abbvie, Celgene, MSD, Novartis, Pfizer and UCB. Stefan Siebert has received honoraria or research funding from AbbVie, Pfizer, Janssen, Novartis, UCB, Celgene, Boehringer Ingelheim and BMS.

Compliance with Ethics Guidelines. This article is based on previously conducted studies and does not contain any studies with human participants or animals performed by any of the authors.

Open Access. This article is distributed under the terms of the Creative Commons Attribution-NonCommercial 4.0 International License (http://creativecommons.org/licenses/ by-nc/4.0/), which permits any noncommercial use, distribution, and reproduction in any medium, provided you give appropriate credit to the original author(s) and the source, provide a link to the Creative Commons license, and indicate if changes were made.

\section{REFERENCES}

1. van der Linden S, Valkenburg HA, Cats A. Evaluation of diagnostic criteria for ankylosing spondylitis. A proposal for modification of the New York criteria. Arthritis Rheum. 1984;27(4):361-8.

2. Khan MA, van der Linden SM, Kushner I, Valkenburg HA, Cats A. Spondylitic disease without radiologic evidence of sacroiliitis in relatives of HLAB27 positive ankylosing spondylitis patients. Arthritis Rheum. 1985;28(1):40-3.

3. Rudwaleit M, Landewe R, van der Heijde D, et al. The development of Assessment of SpondyloArthritis International Society classification criteria for axial spondyloarthritis (part I): classification of paper patients by expert opinion including uncertainty appraisal. Ann Rheum Dis. 2009;68(6):770-6.

4. Rudwaleit M, van der Heijde D, Landewe R, et al. The development of Assessment of SpondyloArthritis International Society classification criteria for axial spondyloarthritis (part II): validation and final selection. Ann Rheum Dis. 2009;68(6):777-83.

5. Deodhar A, Reveille JD, van den Bosch F, et al. The concept of axial spondyloarthritis: joint statement of the Spondyloarthritis Research and Treatment Network and the Assessment of SpondyloArthritis International Society in response to the US Food and Drug Administration's comments and concerns. Arthritis Rheumatol. 2014;66(10):2649-56.

6. Akkoc N, Khan MA. ASAS classification criteria for axial spondyloarthritis: time to modify. Clin Rheumatol. 2016;35(6):1415-23.

7. van der Linden $\mathrm{S}$, Akkoc N, Brown MA, Robinson PC, Khan MA. The ASAS criteria for axial spondyloarthritis: strengths, weaknesses, and proposals for a way forward. Curr Rheumatol Rep. 2015;17(9):62.

8. Robinson PC, Wordsworth BP, Reveille JD, Brown MA. Axial spondyloarthritis: a new disease entity, not necessarily early ankylosing spondylitis. Ann Rheum Dis. 2013;72(2):162-4.

9. Akkoc N, Khan MA. Looking into the new ASAS classification criteria for axial spondyloarthritis through the other side of the glass. Curr Rheumatol Rep. 2015;17(6):515.

10. Deodhar A, Strand V, Kay J, Braun J. The term 'nonradiographic axial spondyloarthritis' is much more important to classify than to diagnose patients with axial spondyloarthritis. Ann Rheum Dis. 2016;75(5):791-4.

11. Robinson PC, Benham H. Advances in classification, basic mechanisms and clinical science in ankylosing spondylitis and axial spondyloarthritis. Intern Med J. 2015;45(2):127-33.

12. Braun J, van der Heijde D. Imaging and scoring in ankylosing spondylitis. Best Pract Res Clin Rheumatol. 2002;16(4):573-604.

13. Creemers MC, Franssen MJ, van't Hof MA, Gribnau FW, van de Putte LB, van Riel PL. Assessment of outcome in ankylosing spondylitis: an extended radiographic scoring system. Ann Rheum Dis. 2005;64(1):127-9.

14. Ramiro S, Stolwijk C, van Tubergen A, et al. Evolution of radiographic damage in ankylosing spondylitis: a 12 year prospective follow-up of the OASIS study. Ann Rheum Dis. 2015;74(1):52-9.

15. Wendling D, Claudepierre P, Pham T, Loeuille D, Prati C. MRI in axial spondyloarthritis: from light to shadow? Jt Bone Spine. 2015;82(5):302-4. 
16. Maksymowych WP. MRI in ankylosing spondylitis. Curr Opin Rheumatol. 2009;21(4):313-7.

17. Rudwaleit M, Jurik AG, Hermann KG, et al. Defining active sacroiliitis on magnetic resonance imaging (MRI) for classification of axial spondyloarthritis: a consensual approach by the ASAS/OMERACT MRI group. Ann Rheum Dis. 2009;68(10):1520-7.

18. Lambert RG, Bakker PA, van der Heijde D, et al. Defining active sacroiliitis on MRI for classification of axial spondyloarthritis: update by the ASAS MRI working group. Ann Rheum Dis. 2016;75(11):1958-63.

19. de Winter J, de Hooge M, van de Sande M, et al. Magnetic resonance imaging of the sacroiliac joints indicating sacroiliitis according to the Assessment of SpondyloArthritis International Society definition in healthy individuals, runners, and women with postpartum back pain. Arthritis Rheumatol. 2018;70(7):1042-8.

20. Varkas G, de Hooge M, Renson T, et al. Effect of mechanical stress on magnetic resonance imaging of the sacroiliac joints: assessment of military recruits by magnetic resonance imaging study. Rheumatology (Oxford). 2018;57(3):508-13.

21. Weber U, Jurik AG, Zejden A, et al. Frequency and anatomic distribution of magnetic resonance imaging features in the sacroiliac joints of young athletes: exploring "background noise" toward a data-driven definition of sacroiliitis in early spondyloarthritis. Arthritis Rheumatol. 2018;70(5):736-45.

22. Baraliakos X, Heldmann F, Callhoff J, et al. Which spinal lesions are associated with new bone formation in patients with ankylosing spondylitis treated with anti-TNF agents? A long-term observational study using MRI and conventional radiography. Ann Rheum Dis. 2014;73(10):1819-25.

23. Hermann KG, Baraliakos $X$, van der Heijde DM, et al. Descriptions of spinal MRI lesions and definition of a positive MRI of the spine in axial spondyloarthritis: a consensual approach by the ASAS/OMERACT MRI study group. Ann Rheum Dis. 2012;71(8):1278-88.

24. Truong SL, Saad NF, Robinson PC, et al. Consensus statements on the imaging of axial spondyloarthritis in Australia and New Zealand. J Med Imaging Radiat Oncol. 2017;61(1):58-69.

25. de Hooge $\mathrm{M}$, van den Berg R, Navarro-Compan V, et al. Magnetic resonance imaging of the sacroiliac joints in the early detection of spondyloarthritis: no added value of gadolinium compared with short tau inversion recovery sequence. Rheumatology (Oxford). 2013;52(7):1220-4.

26. Hermann KG, Landewe RB, Braun J, van der Heijde DM. Magnetic resonance imaging of inflammatory lesions in the spine in ankylosing spondylitis clinical trials: is paramagnetic contrast medium necessary? J Rheumatol. 2005;32(10):2056-60.

27. Robinson PC, Bird P, Lim I, et al. Consensus statement on the investigation and management of non-radiographic axial spondyloarthritis (nraxSpA). Int J Rheum Dis. 2014;17(5):548-56.

28. Bennett AN, McGonagle D, O'Connor P, et al. Severity of baseline magnetic resonance imagingevident sacroiliitis and HLA-B27 status in early inflammatory back pain predict radiographically evident ankylosing spondylitis at eight years. Arthritis Rheum. 2008;58(11):3413-8.

29. Rudwaleit M, Schwarzlose S, Hilgert ES, Listing J, Braun J, Sieper J. MRI in predicting a major clinical response to anti-tumour necrosis factor treatment in ankylosing spondylitis. Ann Rheum Dis. 2008;67(9):1276-81.

30. Bradbury LA, Hollis KA, Gautier B, et al. Diffusionweighted imaging is a sensitive and specific magnetic resonance sequence in the diagnosis of ankylosing spondylitis. J Rheumatol. 2018;45(6):771-8.

31. Sengupta R, Marzo-Ortega H, McGonagle D, Wadeley A, Bennett AN, British Society for Spondyloarthritis. Short-term repeat magnetic resonance imaging scans in suspected early axial spondyloarthritis are clinically relevant only in HLA-B27-positive male subjects. J Rheumatol. 2018;45(2):202-5.

32. Bakker PA, Ramiro S, Ez-Zaitouni Z, et al. Is it useful to repeat MRI of the sacroiliac joints after three months or one year in the diagnostic process of patients with chronic back pain suspected of axial spondyloarthritis? Arthritis Rheumatol. 2018. https://doi.org/10.1002/art.40718.

33. Gong Y, Zheng N, Chen SB, et al. Ten years' experience with needle biopsy in the early diagnosis of sacroiliitis. Arthritis Rheum. 2012;64(5):1399-406.

34. de Koning A, de Bruin F, van den Berg R, et al. Lowdose CT detects more progression of bone formation in comparison to conventional radiography in patients with ankylosing spondylitis: results from the SIAS cohort. Ann Rheum Dis. 2018;77(2):293-9.

35. Baraliakos X, Regel A, Kiltz U, et al. Patients with fibromyalgia rarely fulfil classification criteria for axial spondyloarthritis. Rheumatology (Oxford). 2018;57(9):1541-7. 
36. Roussou E, Ciurtin C. Clinical overlap between fibromyalgia tender points and enthesitis sites in patients with spondyloarthritis who present with inflammatory back pain. Clin Exp Rheumatol. 2012;30(6 Suppl 74):24-30.

37. Macfarlane GJ, Barnish MS, Pathan E, et al. Co-occurrence and characteristics of patients with axial spondyloarthritis who meet criteria for fibromyalgia: results from a UK National Register. Arthritis Rheumatol. 2017;69(11):2144-50.

38. Sieper J, Lenaerts J, Wollenhaupt J, et al. Efficacy and safety of infliximab plus naproxen versus naproxen alone in patients with early, active axial spondyloarthritis: results from the double-blind, placebo-controlled INFAST study, Part 1. Ann Rheum Dis. 2014;73(1):101-7.

39. Kroon FP, van der Burg LR, Ramiro S, et al. Nonsteroidal antiinflammatory drugs for axial spondyloarthritis: a Cochrane review. J Rheumatol. 2016;43(3):607-17.

40. Coxib and traditional NSAID Trialists' (CNT) Collaboration, Bhala N, Emberson J, et al. Vascular and upper gastrointestinal effects of non-steroidal antiinflammatory drugs: meta-analyses of individual participant data from randomised trials. Lancet. 2013;382(9894):769-79.

41. Trelle S, Reichenbach S, Wandel S, et al. Cardiovascular safety of non-steroidal anti-inflammatory drugs: network meta-analysis. BMJ. 2011;342:c7086.

42. Bonner GF, Walczak M, Kitchen L, Bayona M. Tolerance of nonsteroidal antiinflammatory drugs in patients with inflammatory bowel disease. Am J Gastroenterol. 2000;95(8):1946-8.

43. Baraliakos X, Kiltz U, Peters S, et al. Efficiency of treatment with non-steroidal anti-inflammatory drugs according to current recommendations in patients with radiographic and non-radiographic axial spondyloarthritis. Rheumatology (Oxford). 2017;56(1):95-102.

44. Wanders A, Landewe R, Dougados M, Mielants H, van der Linden S, van der Heijde D. Association between radiographic damage of the spine and spinal mobility for individual patients with ankylosing spondylitis: can assessment of spinal mobility be a proxy for radiographic evaluation? Ann Rheum Dis. 2005;64(7):988-94.

45. Sieper J, Listing J, Poddubnyy D, et al. Effect of continuous versus on-demand treatment of ankylosing spondylitis with diclofenac over 2 years on radiographic progression of the spine: results from a randomised multicentre trial (ENRADAS). Ann Rheum Dis. 2016;75(8):1438-43.
46. Haibel H, Fendler C, Listing J, Callhoff J, Braun J, Sieper J. Efficacy of oral prednisolone in active ankylosing spondylitis: results of a double-blind, randomised, placebo-controlled short-term trial. Ann Rheum Dis. 2014;73(1):243-6.

47. Braun J, Bollow M, Seyrekbasan F, et al. Computed tomography guided corticosteroid injection of the sacroiliac joint in patients with spondyloarthropathy with sacroiliitis: clinical outcome and followup by dynamic magnetic resonance imaging. J Rheumatol. 1996;23(4):659-64.

48. Braun J, Zochling J, Baraliakos X, et al. Efficacy of sulfasalazine in patients with inflammatory back pain due to undifferentiated spondyloarthritis and early ankylosing spondylitis: a multicentre randomised controlled trial. Ann Rheum Dis. 2006;65(9):1147-53.

49. Haibel H, Brandt HC, Song IH, et al. No efficacy of subcutaneous methotrexate in active ankylosing spondylitis: a 16-week open-label trial. Ann Rheum Dis. 2007;66(3):419-21.

50. Akkoc N, van der Linden S, Khan MA. Ankylosing spondylitis and symptom-modifying vs diseasemodifying therapy. Best Pract Res Clin Rheumatol. 2006;20(3):539-57.

51. Jones A, Ciurtin C, Ismajli M, Leandro $M$, Sengupta $\mathrm{R}$, Machado PM. Biologics for treating axial spondyloarthritis. Expert Opin Biol Ther. 2018;18(6):641-52.

52. van der Heijde D, Ramiro S, Landewe R, et al. 2016 update of the ASAS-EULAR management recommendations for axial spondyloarthritis. Ann Rheum Dis. 2017;76(6):978-91.

53. Ward MM, Deodhar A, Akl EA, et al. American College of Rheumatology/Spondylitis Association of America/Spondyloarthritis Research and Treatment Network 2015 recommendations for the treatment of ankylosing spondylitis and nonradiographic axial spondyloarthritis. Arthritis Rheumatol. 2016;68(2):282-98.

54. Smolen JS, Schols M, Braun J, et al. Treating axial spondyloarthritis and peripheral spondyloarthritis, especially psoriatic arthritis, to target: 2017 update of recommendations by an international task force. Ann Rheum Dis. 2018;77(1):3-17.

55. Sieper J, van der Heijde D, Dougados M, et al. A randomized, double-blind, placebo-controlled, sixteen-week study of subcutaneous golimumab in patients with active nonradiographic axial spondyloarthritis. Arthritis Rheumatol. 2015;67(10):2702-12. 
56. Sieper J, van der Heijde D, Dougados M, et al. Efficacy and safety of adalimumab in patients with non-radiographic axial spondyloarthritis: results of a randomised placebo-controlled trial (ABILITY-1). Ann Rheum Dis. 2013;72(6):815-22.

57. Dougados M, van der Heijde D, Sieper J, et al. Symptomatic efficacy of etanercept and its effects on objective signs of inflammation in early nonradiographic axial spondyloarthritis: a multicenter, randomized, double-blind, placebo-controlled trial. Arthritis Rheumatol. 2014;66(8):2091-102.

58. Landewe R, Braun J, Deodhar A, et al. Efficacy of certolizumab pegol on signs and symptoms of axial spondyloarthritis including ankylosing spondylitis: 24-week results of a double-blind randomised placebo-controlled phase 3 study. Ann Rheum Dis. 2014;73(1):39-47.

59. Navarro-Compan V, Plasencia-Rodriguez C, de Miguel E, Diaz Del Campo P, Balsa A, Gratacos J. Switching biological disease-modifying antirheumatic drugs in patients with axial spondyloarthritis: results from a systematic literature review. RMD Open. 2017;3(2):e000524.

60. Brown MA, Bird PA, Robinson PC, et al. Evaluation of the effect of baseline MRI sacroiliitis and C reactive protein status on etanercept treatment response in non-radiographic axial spondyloarthritis: a post hoc analysis of the EMBARK study. Ann Rheum Dis. 2018;77(7):1091-3.

61. Maneiro JR, Souto A, Salgado E, Mera A, GomezReino JJ. Predictors of response to TNF antagonists in patients with ankylosing spondylitis and psoriatic arthritis: systematic review and meta-analysis. RMD Open. 2015;1(1):e000017.

62. Ghosh N, Ruderman EM. Nonradiographic axial spondyloarthritis: clinical and therapeutic relevance. Arthritis Res Ther. 2017;19(1):286.

63. Robinson PC, Brown MA. The window of opportunity: a relevant concept for axial spondyloarthritis. Arthritis Res Ther. 2014;16(3):109.

64. Flouri ID, Markatseli TE, Boki KA, et al. Comparative analysis and predictors of 10-year tumor necrosis factor inhibitors drug survival in patients with spondyloarthritis: first-year response predicts longterm drug persistence. J Rheumatol. 2018;45(6):785-94.

65. Glintborg B, Ostergaard M, Krogh NS, et al. Clinical response, drug survival and predictors thereof in 432 ankylosing spondylitis patients after switching tumour necrosis factor alpha inhibitor therapy: results from the Danish nationwide DANBIO registry. Ann Rheum Dis. 2013;72(7):1149-55.
66. Yahya F, Gaffney K, Hamilton L, et al. Tumour necrosis factor inhibitor survival and predictors of response in axial spondyloarthritis-findings from a United Kingdom cohort. Rheumatology (Oxford). 2018;57(4):619-24.

67. Baraliakos X, Listing J, Brandt J, et al. Clinical response to discontinuation of anti-TNF therapy in patients with ankylosing spondylitis after 3 years of continuous treatment with infliximab. Arthritis Res Ther. 2005;7(3):R439-44.

68. Fong W, Holroyd C, Davidson B, et al. The effectiveness of a real life dose reduction strategy for tumour necrosis factor inhibitors in ankylosing spondylitis and psoriatic arthritis. Rheumatology (Oxford). 2016;55(10):1837-42.

69. Haroon N, Inman RD, Learch TJ, et al. The impact of tumor necrosis factor alpha inhibitors on radiographic progression in ankylosing spondylitis. Arthritis Rheum. 2013;65(10):2645-54.

70. Molnar C, Scherer A, Baraliakos X, et al. TNF blockers inhibit spinal radiographic progression in ankylosing spondylitis by reducing disease activity: results from the Swiss Clinical Quality Management cohort. Ann Rheum Dis. 2018;77(1):63-9.

71. Machado P. Anti-tumor necrosis factor and new bone formation in ankylosing spondylitis: the controversy continues. Arthritis Rheum. 2013;65(10):2537-40.

72. Baeten D, Sieper J, Braun J, et al. Secukinumab, an interleukin-17A inhibitor, in ankylosing spondylitis. N Engl J Med. 2015;373(26):2534-48.

73. Sieper J, Deodhar A, Marzo-Ortega H, et al. Secukinumab efficacy in anti-TNF-naive and anti-TNFexperienced subjects with active ankylosing spondylitis: results from the MEASURE 2 Study. Ann Rheum Dis. 2017;76(3):571-92.

74. Deodhar AA, Dougados M, Baeten DL, et al. Effect of secukinumab on patient-reported outcomes in patients with active ankylosing spondylitis: a phase III randomized trial (MEASURE 1). Arthritis Rheumatol. 2016;68(12):2901-10.

75. Braun J, Baraliakos X, Deodhar A, et al. Effect of secukinumab on clinical and radiographic outcomes in ankylosing spondylitis: 2-year results from the randomised phase III MEASURE 1 study. Ann Rheum Dis. 2017;76(6):1070-7.

76. Marzo-Ortega H, Sieper J, Kivitz A, et al. Secukinumab provides sustained improvements in the signs and symptoms of active ankylosing spondylitis with high retention rate: 3-year results from the phase III trial, MEASURE 2. RMD Open. 2017;3(2):e000592. 
77. Baraliakos X, Borah B, Braun J, et al. Long-term effects of secukinumab on MRI findings in relation to clinical efficacy in subjects with active ankylosing spondylitis: an observational study. Ann Rheum Dis. 2016;75(2):408-12.

78. van der Heijde D, Cheng-Chung Wei J, Dougados $\mathrm{M}$, et al. Ixekizumab, an interleukin-17A antagonist in the treatment of ankylosing spondylitis or radiographic axial spondyloarthritis in patients previously untreated with biological disease-modifying anti-rheumatic drugs (COAST-V): 16 week results of a phase 3 randomised, double-blind, active-controlled and placebo-controlled trial. Lancet. 2018;392(10163):2441-51.

79. Deodhar A, Poddubnyy D, Pacheco-Tena C, et al. Efficacy and safety of ixekizumab in the treatment of radiographic axial spondyloarthritis: 16 week results of a phase 3 randomized, double-blind, placebo controlled trial in patients with prior inadequate response or intolerance to tumor necrosis factor inhibitors. Arthritis Rheumatol. 2018. https://doi.org/10.1002/art.40753.

80. Baeten D, Ostergaard M, Wei JC, et al. Risankizumab, an IL-23 inhibitor, for ankylosing spondylitis: results of a randomised, double-blind, placebocontrolled, proof-of-concept, dose-finding phase 2 study. Ann Rheum Dis. 2018;77(9):1295-302.

81. Deodhar A, Gensler LS, Sieper J, et al. Three multicenter, randomized, double-blind, placebo-controlled studies evaluating the efficacy and safety of ustekinumab in axial spondyloarthritis. Arthritis Rheumatol. 2019;71(2):258-70.
82. Siebert S, Millar NL, McInnes IB. Why did IL-23p19 inhibition fail in AS: a tale of tissues, trials or translation? Ann Rheum Dis. 2018. https://doi.org/ 10.1136/annrheumdis-2018-213654.

83. van der Heijde D, Deodhar A, Wei JC, et al. Tofacitinib in patients with ankylosing spondylitis: a phase II, 16-week, randomised, placebo-controlled, dose-ranging study. Ann Rheum Dis. 2017;76(8):1340-7.

84. van der Heijde D, Baraliakos X, Gensler LS, et al. Efficacy and safety of filgotinib, a selective Janus kinase 1 inhibitor, in patients with active ankylosing spondylitis (TORTUGA): results from a randomised, placebo-controlled, phase 2 trial. Lancet. 2018;392(10162):2378-87.

85. McInnes IB, Siebert S. The extending scope of kinase inhibition in immune diseases. Lancet. 2018;392(10162):2328-31.

86. Costello ME, Ciccia F, Willner D, et al. Brief report: intestinal dysbiosis in ankylosing spondylitis. Arthritis Rheumatol. 2015;67(3):686-91.

87. Costello ME, Robinson PC, Benham H, Brown MA. The intestinal microbiome in human disease and how it relates to arthritis and spondyloarthritis. Best Pract Res Clin Rheumatol. 2015;29(2):202-12.

88. Kenna TJ, Robinson PC, Haroon N. Endoplasmic reticulum aminopeptidases in the pathogenesis of ankylosing spondylitis. Rheumatology (Oxford). 2015;54(9):1549-56. 